\title{
Causas de recusa familiar na doação de órgãos e tecidos
}

\section{Causes of family refusal on the organs and tissues donation}

\section{Christielle Lidianne Alencar Marinho', Ana Isabel Cezário de Carvalho Conceição², Rudval Souza da Silva ${ }^{3}$}

'Autora para correspondência. Universidade do Estado da Bahia, Salvador, Bahia, Brasil. ORCID: 0000-0002-3827-5494. christiellealencar@yahoo.com.br 2Universidade do Estado da Bahia, Salvador, Bahia, Brasil. ORCID: 0000-0003-2575-1065. anaisabel.c@hotmail.com ${ }^{3}$ Universidade do Estado da Bahia, Universidade Federal da Bahia, Salvador, Bahia, Brasil. ORCID: 0000-0002-7991-8804. rudvalsouza@yahoo.com.br

RESUMO I INTRODUÇÃO: A taxa de doações de órgãos e tecidos vem crescendo durante os anos. Porém, a não efetivação das doações ainda é alta, sendo o principal fator a recusa familiar. OBJETIVO: Descrever os motivos de recusa familiar para doação de órgãos e tecidos. MÉTODOS: Estudo quantitativo, descritivo, retrospectivo, transversal e exploratório, realizado com 147 prontuários de pacientes potenciais doadores de órgãos nos hospitais de Petrolina-PE, entre os anos de 2013 a 2017, que tiveram a recusa familiar para a doação de órgãos. Para coleta de dados utilizou-se um formulário de pesquisa elaborado pelas autoras. Os dados foram tabulados e armazenados no programa Excel for Windows/2013, compondo o banco de dados da pesquisa. Projeto aprovado pelo Comitê de Ética em Pesquisa da Universidade do Estado da Bahia sob $\mathrm{n}^{\circ}$ 65496017.3.0000.0057. RESULTADOS: Foram analisados 350 prontuários de potenciais doadores os quais a entrevista familiar foi realizada. Para este estudo, foram utilizados apenas os prontuários em que houve a recusa familiar para a doação dos órgãos e tecidos, totalizando 147. As causas mais frequentes foram: corpo íntegro $(36,0 \%)$, desconfiança do processo de doação $(32,6 \%)$, doador contrário em vida $(16,3 \%)$, revolta com atendimento da equipe hospitalar $(4,7 \%)$, demora do processo de doação $(2,7 \%)$, motivos religiosos e não compreensão da morte encefálica (1,3\%). CONCLUSÃO: Percebe-se que os fatores de recusa remetem à falta de informação e divulgação sobre o processo de doação, sendo necessário que campanhas educativas sejam realizadas com o objetivo de esclarecer a população sobre esta temática, visando diminuir as negativas devido à recusa familiar.

\begin{abstract}
INTRODUCTION: The rate of organ and tissue donation has been growing over the years. However, donations are not yet effective, and the main factor is family refusal. OBJECTIVE: Describe the reasons for family refusal to donate organs and tissues. METHODS: A quantitative, descriptive, retrospective, cross-sectional and exploratory study of 147 medical records of potential organ donor patients in Petrolina-PE hospitals from 2013 to 2017 was used. Data collection was done using an elaborated research form by the authors. The data were tabulated and stored in the program Excel for Windows / 2013, composing the search database. Project approved by the Research Ethics Committee of the State University of Bahia under $n^{\circ} 65496017.3 .0000 .0057$. RESULTS: A total of 350 charts of potential donors were analyzed and the family interview was performed. For this study, only the medical records were used, in which there was a family refusal to donate organs and tissues, totaling 147 . The most frequent causes were: intact body $(36.0 \%)$, distrust of the donation process $(32.6$ (16.3\%), hospital staff $(4.7 \%)$, delayed donation $(2.7 \%)$, religious reasons and noncomprehension of brain death (1,3\%). CONCLUSION: It is noticed that the refusal factors refer to the lack of information and dissemination about the donation process, and it is necessary that educational campaigns be carried out with the aim of clarifying the population about this theme, in order to reduce the negative ones due to family refusal.
\end{abstract}

DESCRIPTORS: Brain death. Transplantation. Tissue and organ procurement.

DESCRITORES: Morte encefálica. Transplante. Obtenção

de tecidos e órgãos. 


\section{Introdução}

Devido ao avanço tecnológico no âmbito das ciências da saúde, especialmente quando se trata de transplantes de órgãos e tecidos, este tratamento tornou-se uma alternativa terapêutica para diversas doenças crônicas e/ou incapacitantes promovendo a reabilitação e um aumento na expectativa de vida desses pacientes. Entretanto, muitos conflitos éticos e legais permeiam a doação de órgãos gerando impasses na efetivação do processo ${ }^{1,2}$.

Para que a doação de órgãos e tecidos aconteça, é necessário um potencial doador com diagnóstico de Morte Encefálica (ME), seguido da notificação da Central de Notificação, Captação e Distribuição de Órgãos (CNCDO) e abordagem da equipe junto aos familiares do possível doador ${ }^{2-3}$. Para isto, a Resolução CFM N ${ }^{\circ} 2.173 / 2017^{4}$ define que para determinar a ME é necessário observar alguns parâmetros clínicos, tais como: coma não perceptivo, ausência de atividade supraespinhal e apneia persistente.

Quanto à autorização familiar, a lei 10.211 de 23 de março de $2001^{5}$ deixa claro que a retirada dos órgãos só ocorrerá após a realização de todos os exames e autorização expressa do conjugue ou parente de primeiro grau, maior de idade. Sendo então possível a negação da família caso não seja a favor da doação. A recusa familiar é um dos obstáculos para a não realização do transplante, colaborando com a escassez de órgãos e a consequente diminuição do número de doadores efetivos ${ }^{6}$. $O$ desconhecimento da família com relação ao processo de doação dificulta a realização do da doação ${ }^{7}$.

É notável que a taxa de doações vem crescendo durante os anos, porém, a não efetivação das doações ainda é alta, sendo o principal fator, a recusa familiar. Em 2017, no Brasil, 45\% dos casos da não realização ocorreu pela negativa familiar, em Pernambuco esse número foi $32 \%$, já na Bahia esse percentual chegou a $60 \%$. Apesar de todos os avanços, o processo de transplante esbarra em dificuldades na captação de órgãos ${ }^{8}$.

Conhecer os principais motivos que levam à recusa familiar permite que os profissionais de saúde desenvolvam estratégias para facilitar uma abordagem familiar mais eficaz no momento da entrevista, bem como, no processo de educação e desmistifi- cação dessas informações, visando o aumento da quantidade de doação de órgãos no Brasil. $O$ objetivo do estudo foi descrever, através da análise dos prontuários de potenciais doadores de órgãos, atendidos nos hospitais de Petrolina (PE), as principais causas que levam à recusa familiar para doação de órgãos e tecidos.

\section{Metodologia}

Trata-se de um estudo descritivo, retrospectivo, transversal, exploratório, de natureza quantitativa, desenvolvido nos hospitais da cidade de Petrolina, situada no Estado de Pernambuco, Brasil. Foi realizada coleta de dados de todos os prontuários dos pacientes com possível diagnóstico de morte encefálica, notificados no período de janeiro de 2013 a dezembro de 2017, totalizando 524 prontuários.

Foram adotados como critérios de inclusão: prontuários de pacientes em morte encefálica que iniciaram e deram seguimento ao protocolo de morte encefálica nos hospitais de Petrolina-PE, Brasil. Enquanto os critérios de exclusão foram: prontuários com anotações incompletas que não permitam a coleta de informações necessárias à composição do banco de dados da pesquisa e aqueles que tinham contraindicação clínica para a doação de órgãos, como por exemplo, sorologias positivas, infecções, idade avançada, dentre outras doenças associadas e a ocorrência de parada cardiorrespiratória antes do fechamento do protocolo de ME.

A coleta de dados ocorreu durante os meses de outubro de 2017 a janeiro de 2018 , utilizou-se como instrumento de coleta, um formulário de pesquisa elaborado pelas próprias autoras. Após preenchimento, os dados foram tabulados e armazenados no programa Excel for Windows/2013, compondo o banco de dados da pesquisa.

Do total de 524 prontuários coletados, foram excluídos 102 por falta de informações completas e 72 por possuírem contraindicação clínica para a doação, totalizando 350 prontuários.

Por se tratar de pesquisa com dados secundários foi solicitado autorização institucional, garantindo a não-utilização das informações em prejuízo das 
pessoas e/ou das comunidades, tendo sido o projeto aprovado pelo Comitê de Ética em Pesquisa da Universidade do Estado da Bahia sob n 65496017.3.0000.0057.

\section{Resultados}

Dos 350 prontuários de pacientes potenciais doadores, 147 recusaram a doação, representando $42 \%$ dos casos. Dentre os motivos citados nos prontuários para a recusa, a manutenção do corpo íntegro foi descrito em $36 \%$ das situações, seguido da desconfiança do processo de doação $(32,6 \%)$ e o fato de o doador ser contrário em vida à doação (24\%) (tabela 1 ).

Tabela 1. Motivos de recusa familiar para doação de órgãos e tecidos. Petrolina (PE), Brasil

\begin{tabular}{lc}
\hline Motivos de recusa familiar & $53(36,0 \%)$ \\
\hline Corpo íntegro & $48(32,6 \%)$ \\
Desconfiança do processo de doação & $24(16,3 \%)$ \\
Doador contrário em vida & $7(4,7 \%)$ \\
Revolta com atendimento hospitalar & $4(2,7 \%)$ \\
Demora do processo de doação & $2(1,3 \%)$ \\
Motivos religiosos & $2(1,3 \%)$ \\
Não compreensão da ME & $7(4,7 \%)$ \\
\hline
\end{tabular}

\section{Discussão}

A doação de órgãos consiste na retirada de um ou mais órgãos e/ou tecidos de um indivíduo vivo ou falecido para a finalidade de transplantes, e este é considerado uma solução terapêutica para alguns pacientes em estado terminal. Desta forma, para que ocorra a doação é necessário um doador vivo ou falecido, com diagnóstico de $M E$, e autorização familiar ${ }^{1,5}$. A doação de órgãos de doadores post-mortem pode beneficiar mais de dez pacientes receptores mediante a doação de múltiplos órgãos e tecidos.

O transplante pode ser a última alternativa para muitas pessoas com doenças crônicas, todavia, o tempo de espera em lista única é determinante para a sobrevida desse paciente, pois o número de doadores/doação ainda é insuficiente fazendo com que esses indivíduos passem muito tempo aguardando por um órgão, podendo ir a óbito sem ter tido a chance de receber 0 enxerto ${ }^{\circ}$.

Além da insuficiente oferta, a recusa familiar é um dos principais motivos da não realização desse procedimento. Em Pernambuco, no ano de 2017 ocorreram 588 notificações de $M E$, onde apenas 188 $(32,0 \%)$ transplantes foram realizados, as principais causas para não efetivação foram a recusa familiar $150(25,5 \%)$, parada cardiorrespiratória $(1,0 \%)$, contraindicação médica $148(25,1 \%)$ e outros motivos $66(11,1 \%)^{8}$.

Foi possível identificar que a principal causa de recusa familiar se refere à manutenção do corpo íntegro $(36,0 \%)$. Os familiares acreditam que o corpo trata-se de algo intocável, julgando importante o culto ao corpo presente, e dessa forma este deve permanecer 
inviolável ${ }^{9}$. Ao manipular esse corpo para retirada dos órgãos, os mesmos interpretam como falta de cuidado e respeito ao falecido, e por não enxergarem o corpo como algo material, acabam resistindo à doação acreditando que a aceitação iria causar mais dor e sofrimento aos familiares ${ }^{b}$.

A religiosidade e a cultura individual também se revelam como motivos para a não aceitação da manipulação do corpo, pois no imaginário dessas famílias, ao manuseá-lo, o mesmo perde sua integridade, ficando deformado e não sendo possível devolvê-lo como veio ao mundo ${ }^{10}$.

Outro motivo que interfere na decisão dos familiares é a desconfiança sobre o processo de doação. $O$ interesse da equipe de captação leva a incertezas, dúvidas e inseguranças quanto à decisão de doar. A família acredita que o empenho pela doação e os cuidados excessivos com o paciente, tem como objetivo a comercialização dos órgãos. Em alguns estudos, fica evidente nos relatos dos familiares o medo do tráfico de órgãos, que pode acontecer com seu ente querido, o que leva a pensar que a morte do paciente possa ser antecipada ou induzida para atender 0 interesse da equipe ${ }^{10-11}$. Incertezas desse tipo ocorrem quando os parentes não são informados sobre o estado de saúde do paciente em tempo integral, e só são informados quando o diagnóstico de ME já está concluído ${ }^{10-11}$.

Conhecer a vontade do doador influencia significantemente na tomada de decisão dos familiares, e uma das principais causas de recusa foi o conhecimento da falta de desejo do ente em vida à doação $(16,3 \%)$. Quando os familiares conhecem a vontade do falecido, esses tendem a considerá-la ${ }^{2-3}$. Alguns familiares negam a doação por receio de ser uma decisão supostamente contrária ao desejo do ente ${ }^{6}$. Já quando conhecem o desejo de doar e assim fazem, reduzem o sentimento de culpa por supostamente não respeitar o corpo do morto. Em contrapartida, quando se negam a realizar essa vontade, entendem como um desrespeito muito maior que o da não manipulação do corpo ${ }^{1,3}$.

Estudos abordam a importância de conhecer a vontade do doador ainda em vida. Encontramo-nos numa sociedade em que falar de morte não é comum. Assim, as pessoas não pensam na possiblidade da morte e consequentemente não falam em vida sobre sua opinião ou desejo em relação a doação dos órgãos, o que dificulta a decisão familiar no momento necessário. Campanhas educativas e de divulgação sobre o tema se tornam uma ferramenta facilitadora no momento da decisão familiar ${ }^{2-3}$.

A revolta com o atendimento hospitalar $(4,7 \%)$ também se apresentou como uma causa influenciadora na tomada de decisão. A prestação dos serviços nos hospitais considerada insatisfatória, muitas vezes por consequência da superlotação resulta em mal atendimento, gera revolta nos familiares e consequentemente recusa da doação de órgãos ${ }^{1,6}$.

A relação entre os profissionais de saúde com a família e paciente também interfere no processo de doação de órgãos. Quando os familiares percebem a falta de empenho no cuidado ao seu ente, falta de acolhimento e esclarecimento sobre o quadro clínico, decidem por não realizar a doação, pois não conseguem dissociar a sua decisão do atendimento recebido". A falta de esclarecimento gera dúvidas e a recusa para doação muitas vezes acontece como forma de repúdio pelo atendimento recebido ${ }^{10-11}$.

O enfermeiro é um membro da equipe de saúde que pode estar ligado ao potencial doador de órgãos tanto na assistência, dentro das Unidades de Terapia Intensiva (UTI) e emergências, quanto como membro das centrais de transplantes. Assim, este é responsável pelo acolhimento aos familiares destes pacientes e para tal é importante que neste momento seja respeitado o luto e as informações sejam esclarecedoras, para que a decisão familiar no tocante à doação seja tomada de forma consciente.

A demora no processo de doação aparece com 2,7\% dentre os motivos de recusa familiar. Os sentimentos dos familiares enquanto aguardam a liberação do corpo para a preparação do velório é caracterizado como um momento desgastante, as famílias vivenciam sentimentos de ansiedade e nervosismo devido à demora de todo o processo burocrático ${ }^{11}$.

O processo de retirada de órgãos e tecidos exige certo tempo, pois além de necessitar recrutar o receptor da lista de espera, vários exames são realizados, tanto no doador quanto no receptor, para que o procedimento seja feito. Além de enfrentarem a dor da perda, estes ainda têm que lidar com os atrasos na liberação do corpo, a falta de acolhi- 
mento, o fato de não compreenderem o processo de retirada dos órgãos e a decisão de aceitar ou não a doação, e como forma de amenizar o sofrimento, eles tendem a não aceitar a doação $0^{6,12}$.

Em relação a não compreensão da morte encefálica por motivos religiosos $(1,3 \%)$, os familiares possuem dificuldade para entender a ME como uma morte real, pois ao se deparar com um corpo apresentando temperatura normal, com movimentos respiratórios e batimentos cardíacos, acarreta em dúvidas quanto ao real diagnóstico de morte, culminando na crença da reversão da $M E^{9,13}$. Diante de um coração batendo o familiar acredita que Deus pode realizar um milagre e reverter a condição do ente.

O processo de luto, quase sempre, envolve questões religiosas, tornando-se como um ponto de apoio para a superação de uma perda, da mesma for$\mathrm{ma}$, muitos familiares usam a crença religiosa como escape ou desculpa para justificar a dificuldade de assumir a decisão em relação à recusa de doação, pois alegam que estariam esperando um milagre ou que o consentimento da doação seria o mesmo que autorizar ou decretar a morte do parente $e^{1,6,10}$. No Brasil, nenhuma religião adota uma postura desfavorável em relação à doação de órgãos e tecidos, apenas realizam interpretações pessoais sobre os livros doutrinários e consideram a opinião do líder religioso ${ }^{7}$.

Devido a forma súbita que na maioria das vezes essas mortes acontecem, geralmente causadas por acidentes de trânsito, ferimentos por armas de fogo, trauma cranioencefálico, entre outras causas repentinas, acaba por gerar comoção familiar, não permitindo a família um tempo hábil para assimilar todos os fatos ocorridos, resultando em negação da ME e consequentemente da doação de órgãos ${ }^{9,13}$.

É positiva a relação entre entender o diagnóstico e aceitar a doação. As famílias que compreendem, aceitam doar abreviando a dor e a espera inútil de um milagre, facilitando o processo. A forma de comunicação, linguagem acessível dos profissionais de saúde, podem garantir uma escolha consciente e segura no tocante a doação de órgãos. $O$ direito da família à informação deve ser assegurado, transmitindo veracidade sobre o diagnóstico de $M E$, possibilitando a doação $0^{6,13}$.
Ações de educação permanente com a equipe hospitalar com o intuito de melhorar o acolhimento familiar, independente do estado de saúde do paciente, é de extrema importância para a humanização da assistência. Quando o familiar está satisfeito e confia no serviço, as chances de autorizar a doação são maiores.

\section{Conclusão}

Percebe-se que a falta de informações quanto ao processo de doação e transplante interfere de forma negativa para a doação de órgãos. Os motivos mais frequentes para a recusa foram relacionados a crenças religiosas, preocupação com a violação/ manipulação do corpo, esperança da reversão do quadro clínico e a não satisfação com o atendimento prestado.

Conhecer a vontade do doador torna-se um fator de interferência na efetivação da doação de órgãos, pois a família tende a considera-la. A demora do processo de doação para liberação do corpo e a não compreensão da morte encefálica também interferiram de forma significativa para a recusa familiar.

O tema também precisa ser bem discutido entre os profissionais de saúde, uma vez que são estes profissionais que estão em contato direto com a família no momento da declaração do óbito. A abordagem baseada no acolhimento, de forma respeitosa e esclarecedora é essencial para o aumento das taxas de doação de órgãos e a diminuição das filas de espera.

Desta forma, conhecer os motivos que envolvem a recusa pode contribuir para respaldar o planejamento de ações visando a promoção da doação de órgãos e tecidos, colaborando, deste modo, para a redução da fila de espera.

\section{Contribuição dos autores}

Marinho CLA contribuiu na concepção do projeto, coleta, análise e interpretação dos dados, redação do artigo e aprovação da versão final a ser publicada. Conceição AICC contribuiu na concepção do projeto, análise e interpretação dos dados e redação do artigo. Silva RS contribuiu na redação, revisão crítica relevante do conteúdo e aprovação da versão final a ser publicada. 


\section{Conflitos de interesses}

Nenhum conflito financeiro, legal ou político envolvendo terceiros (governo, empresas e fundações privadas, etc.) foi declarado para nenhum aspecto do trabalho submetido (incluindo mas não limitandose a subvenções e financiamentos, conselho consultivo, desenho de estudo, preparação de manuscrito, análise estatística, etc).

\section{Referências}

1. Barreto BS, Santana RJB, Nogueira EC, Fernandez BO, Brito FPG. Fatores relacionados à não doação de órgãos de potenciais doadores no estado de Sergipe, Brasil. Rev Bras Pesq Saúde. 2016;18(3):40-48. doi: 10.21722/rbps. v18i3.15741

2. Bonetti CE, Boes AA, Lazzari DD, Busana JA, Maestris E, Bresolin P. Doação de órgãos e tecidos e motivos de sua não efetivação. Rev Enferm UFPE on line. 2017;1 1(Supl 9):3533-41. doi: 10.5205/revol.10620-94529-1$\underline{S M .1109 \text { sup } 201705}$

3. Marques FS, Barbosa MDP, Ribeiro IM. Doação de órgãos e tecidos para transplante: motivos de não autorização. Cad Pesq. 2013;20(3):93-100.

4. Brasil. Conselho Federal de Medicina. Resolução 2.173/2017 de 15 de dezembro 2017. Define os critérios do diagnóstico de morte encefálica. Brasília: Conselho Federal de Medicina; 2017.

5. Brasil. Presidência da República. Lei $n^{\circ} 10.211 /$ de 23 de março de 2001. Altera dispositivos da lei 9.434, de 4 de fevereiro de 1997, que dispõe sobre a remoção de órgãos, tecidos e partes do corpo humano para fins de transplante e tratamento. Brasília;2001.

6. Cajado MCV, Franco ALS. Doação de órgãos e tecidos para transplantes: impasses subjetivos diante da decisão familiar. Rev Baiana Saúde Pública. 2016;40(2):480-99. doi: 10.22278/2318-2660.2016.v40.n2.a2164

7. Pessoa JLE, Schirmer J, Roza BA. Avaliação das causas de recusa familiar à doação de órgãos e tecidos. Acta Paul Enferm. 2013;26(4):323-30. doi: 10.1590/S0103$\underline{21002013000400005}$

8. Associação Brasileira de Transplante de Órgãos. Registro Brasileiro de Transplante [Internet]. 2017 [acessado em 2018 jan. 10]. Disponível em http://www.abto.org.br/abtov03/ Upload/file/RBT/2017/rbttrim3-leitura.pdf.

9. Lira GG, Pontes CM, Schirmer J, Lima SL. Ponderações de familiares sobre a decisão de recusar a doação de órgãos. Acta Paul Enferm. 2012;25(esp 2):140-5. doi: 10.1590/ S0103-21002012000900022
10. Rosário EN, Pinho LG, Oselame GB, Neves EB. Recusa familiar diante de um potencial doador de órgãos. Cad Saúde Colet. 2013;21 (3):260-6. doi: 10.1590/S1414$\underline{462 \times 2013000300005}$

11. Machado EFS, Andrade JT. Decisão familiar frente à doação de órgãos para transplante no estado do Ceará. Revista Mestrado Profissional em Planejamento em Políticas Públicas. $2011 ; 2: 28-70$.

12. Camatta JAP, Berti HW, Ayres JA, Tonete VLP. Motivos de recusa à doação de órgãos apontados por familiares de pessoas com morte encefálica. JBT J Bras Transpl. $2012 ; 14(3): 1579-1585$.

13. Teixeira RKC, Goncalves TB, Silva JAC. A intenção de doar órgãos é influenciada pelo conhecimento populacional sobre morte encefálica? Rev Bras Rev Intensiva. 201 2;24(3):258-262. doi: 10.1590/S0103$\underline{507 \times 2012000300009}$ 